\title{
Reflecting on reflection: How educators experience the opportunity to talk about supporting student reflection
}

\author{
Dr. Jennifer A Turns, University of Washington \\ Dr. Brook Sattler, University of Washington
}

Dr. Sattler is a Research Scientist for the Center for Engineering Learning \& Teaching (CELT) and a Multi-Campus Coordinator for the Consortium to Promote Reflection in Engineering Education (CPREE) at the University of Washington. Her research interests include understanding and promoting self-authoring engineers.

Dr. Lauren D. Thomas, University of Washington

Dr. Cynthia J. Atman, University of Washington

Cynthia J. Atman is the founding director of the Center for Engineering Learning \& Teaching (CELT), a professor in Human Centered Design \& Engineering, and the inaugural holder of the Mitchell T. \& Lella Blanche Bowie Endowed Chair at the University of Washington. Dr. Atman is co-director of the newly-formed Consortium for Promoting Reflection in Engineering Education (CPREE), funded by a $\$ 4.4$ million grant from the Leona M. and Harry B. Helmsley Charitable Trust. She was director of the NSF-funded Center for the Advancement of Engineering Education (CAEE), a national research center that was funded from 2003-2010. Dr. Atman is the author or co-author on over 115 archival publications. She has been invited to give many keynote addresses, including a Distinguished Lecture at the American Society of Engineering Education (ASEE) 2014 Annual Conference.

Dr. Atman joined the UW in 1998 after seven years on the faculty at the University of Pittsburgh. Her research focuses on engineering education pedagogy, engineering design learning, assessing the consideration of context in engineering design, and understanding undergraduate engineering student pathways. She is a fellow of the American Association for the Advancement of Science (AAAS) and the ASEE. She was the recipient of the 2002 ASEE Chester F. Carlson Award for Innovation in Engineering Education and the 2009 UW David B. Thorud Leadership Award. Dr. Atman holds a Ph.D. in Engineering and Public Policy from Carnegie Mellon University.

Mr. Richard Brown Bankhead III, Highline Community College

Dr. Adam R Carberry, Arizona State University

Dr. Adam Carberry is an assistant professor at Arizona State University in the Fulton Schools of Engineering Polytechnic School. He earned a B.S. in Materials Science Engineering from Alfred University, and received his M.S. and Ph.D., both from Tufts University, in Chemistry and Engineering Education respectively. Dr. Carberry was previously an employee of the Tufts' Center for Engineering Education \& Outreach and manager of the Student Teacher Outreach Mentorship Program (STOMP).

\section{Dr. Kristine R. Csavina, Arizona State University, Polytechnic campus \\ Dr. Patrick Cunningham, Rose-Hulman Institute of Technology \\ Dr. Douglas Karl Faust, Seattle Central College}

$\mathrm{PhD}$ in Physics, professor of Mathematics, physics, astronomy and computer science.

\section{Dr. Trevor Scott Harding, California Polytechnic State University}

Dr. Trevor S. Harding is Professor of Materials Engineering at California Polytechnic State University where he teaches courses in materials design, biomedical materials, and life cycle analysis. He has presented his research on engineering ethics to several universities and to the American Bar Association. He serves as Associate Editor of the journals Advances in Engineering Education and International Journal of Service Learning in Engineering. He serves as program chair for the Community Engagement Division of ASEE. Dr. Harding was invited to deliver a workshop on Ethics in the Engineering Curricula at the 2009 NSF Engineering Awardees Conference and to participate in the NSF Project Based Service Learning 
Summit. He received the 2008 President's Service Learning Award for innovations in the use of service learning at Cal Poly. In 2004 he was named a Templeton Research Fellow by the Center for Academic Integrity. Dr. Harding received both the 1999 Apprentice Faculty Grant and 2000 New Faculty Fellow Award for his contributions to engineering education.

Dr. Ken Yasuhara, Center for Engineering Learning \& Teaching, University of Washington 


\title{
Reflecting on reflection: How educators experience the opportunity to talk about supporting student reflection
}

\begin{abstract}
To explore the general question of ways to help educators become more reflective, this paper focuses on the proposition that one way to help educators be more reflective is to give them an opportunity to discuss (or be interviewed about) an activity they do with students. To address this proposition, we use a "multiple perspectives methodology" featuring essays from seven educators about their experiences of being interviewed about a reflection activity they have done with students. The educators' essays suggest that the interviews were experienced as (1) a reflection opportunity, (2) a chance to reflect on the activity that was the focus of the interview, (3) a chance to reflect on reflection as an educational activity, and (4) a chance to bridge reflection and other points of personal interest. The results presented in this paper provide a basis for suggesting that interviewing educators about activities they use with students is a promising way to support educator reflection.
\end{abstract}

\section{Introduction}

Henderson, Beach, and Finkelstein [1] identified helping educators become increasingly reflective as teachers as a strategy that can help STEM Education better accomplish its goals. This suggestion raises the general question: What are ways to help educators become more reflective? The work of this paper fits into efforts to support educator reflection.

Recently, we have engaged several educators in individual discussions about an educational activity they do with students (specifically, an activity to support student reflection). Our original purpose was to learn more about the activities, but we have seen evidence of the impact such a discussion can have on the educators and their practices. The educators' feedback has been that the opportunity to talk through one of the activities they use with students was enjoyable, challenging, thought-provoking, and even eye-opening. Informal feedback suggests that the educators have viewed the discussion as a chance to reflect themselves. In other words, their feedback has suggested, in response to our general question above, that one way to help educators be more reflective is to give them an opportunity to discuss (or be interviewed about) an activity they do with students. We set out to explore their experiences of being interviewed in order to better understand the interview as a site of educator reflection.

In this paper we will use a "multiple perspectives methodology" [2] to explore the questionhow does being interviewed about an educational activity (specifically, an activity designed to help student reflection) function as a site for educator reflection? A multiple perspectives methodology involves making diverse perspectives visible through first-hand accounts, and then identifying and explaining themes that are illustrated by the diverse perspectives. Core to our paper are first-hand accounts of educators' experiences of being interviewed about their reflection activities. This paper theoretically frames these accounts and illustrates the potential for such interviews to help educators function as reflective practitioners via sequencing and subsequent articulation of themes across the accounts. 


\section{Background and related work}

We start by discussing two visions for the role of reflection in the professional activity of educators. First, we look to Fink, Ambrose, and Wheeler's cycle of professional practice [3], which relies on educators reflecting on their own practice, educational problems, and engaging with other educators on engineering education topics. Second, we examine Brookfield's thoughts on critical reflection, and the impact that the practice can have on the educator's development and what students experience in their classrooms [4]. These two bodies of work provide a basis to understand the purpose of reflection in the professional practice of engineering educators. Fink, Ambrose, and Wheeler direct educator's attention to identifying educational issues. Brookfield explains why critical reflection is a pathway to achieving deeply student-centered education. Later, this paper will show some of the ways that being interviewed about an educational activity (specifically, a reflection activity used with students) contributed toward these visions of engineering educators' professional practices.

\section{Reflection and the Cycle of Professional Practice}

Fink, Ambrose, and Wheeler [3] provide a vision of the activities of engineering educators. They draw comparisons between improving technical practice and improving teaching practice. A major focus is placed on the role of identifying and solving teaching problems as central to the cycle of professional practice.

The core issue of this vision for educators is the identification and resolution of problems. The problem solving process uses knowledge and also creates knowledge. Educators are part of the process of expanding the knowledge base for teaching. Fink and his colleagues also include a description of the kind of knowledge that an educator would draw on in order to identify and solve teaching problems, discuss implications for faculty development that seeks to help educators improve in this problem solving activity, and present case studies of two faculty development centers focusing on the activities supporting the data on how learning has been impacted. This vision is highly linked to the notion of a reflective practitioner [5].

The vision of a cycle of professional practice has been particularly apparent in faculty development efforts. For example, a study of the engineering educator teaching concerns that was situated in the instructional consulting context highlighted the core issues of problem identification and resolution as central to what the educators wanted to do in the consultations [3]. Other papers describing and evaluating particular professional development activities also seem to highlight activities that center on problem solving. For example, Finelli and her colleagues experimentally compared different forms of faculty development and found that providing a ratings report along with a consultation to discuss the report was particularly effective [6]. Tennenberg and Wang [7] and Tennenberg and Fincher [8] have been exploring a "disciplinary commons" approach in which educators work alongside each other to build portfolios documenting their teaching practices and sharing, along the way, the problems they have faced and the resolutions they have reached.

\section{Critical Reflection}

The basic mechanism for critical reflection consists of an educator examining his or her own teaching practices and trying to understand how the teaching practices could be experienced by various student populations in different ways [4]. The importance of critical reflection stems 
from issues of power that are inherent in educational contexts. Teachers have power in that they have the ability and responsibility to allocate resources (i.e., student attention, student effort, teachers own activities) toward helping students achieve certain goals (i.e., learning, grades). Critical reflection is recognition that educators have a responsibility to address these issues with fairness and respect for students, with emphasis on the democratic ideal of helping all students succeed.

For Brookfield, what makes critical reflection necessary is the observation that "what we think are democratic, respectful ways of treating people can be experienced as oppressive and constraining" (p. 1). Brookfield further clarifies that the purpose of critical reflection is to "understand how considerations of power undergird, frame, and distort educational processes and interactions." (p. 8). In his view, teaching is never innocent because the issue of power is always present, but teaching can be naïve if a teacher fails to recognize how issues associated with power (e.g., authority, equality of access) are at play in one's teaching. Critical reflection is a means for becoming less naïve because it guides educators in understanding what and how to be critically reflective.

Examples discussed by Brookfield include how teaching practices, such as the circle and spontaneous discussion, which are likely to be guided by democratic and respectful ideals, can be experienced by students as coercive and unsupportive. The emphasis is on looking past what may have been intended by the educator and looking to what is experienced by students. Brookfield further suggests that the accumulated result of such analyses can be the uncovering of assumptions about teaching and students that may be limiting an effective stance on power in the classroom. An emphasis is placed on the value of viewing practice from different perspectives in order to become more aware of one's own assumptions. Value is given to (1) using autobiography in general and techniques such as peer review, videotaping, and ideological critique; (2) having conversations; and (3) looking at activity through theory. Brookfield emphasizes across these techniques the responsibility of educators to generate from his or her own teaching practice the very information that will form the basis for reflection.

\section{Approach}

A "multiple perspectives methodology" involves making diverse perspectives visible, and then identifying and explaining insights made possible by the diverse perspectives [2]. The perspectives in this study are first-hand phenomenological accounts, in the form of essays, in which educators address the experience of having been interviewed about a reflection activity they have used with engineering students.

The starting point, educators being interviewed

The perspectives (i.e., the essay contributions) in this paper represent educators' experiences of being interviewed about a reflection activity that they have done with students. A resource called "the CPREE discussion kit" (included in Appendix 1) was used to guide a semi-structured interview between the interviewer and the educator.

The work was part of the Consortium to Promote Reflection in Engineering Education (CPREE), and interviews are central to CPREE's activity. A central goal of the consortium is to document ways in which educators in engineering are currently supporting student reflection. The work 
emphasizes and honors contributor's perspective and their own application of reflection in engineering education. Interviews are a way to document that information. The aim is not to push a particular perspective or theoretical framework, but rather to document and understand what is happening in engineering classrooms and educational spaces. This socially constructed reality has the opportunity to tell us a lot about the practical implications of reflection in engineering education.

The central question of the CPREE discussion kit focuses attention on one instance in which the educator has completed a reflection activity with students. We intentionally aim the educator's attention to one specific instance in order to capture the necessary details for the activity to be recreated by another educator in a different context. Warm-up questions explore the educator's broad perspective on reflection and the concluding questions connect up their activity, loosely to the operationalization of reflection presented by Turns et al. [9]. The interview is designed to range from 30 minutes to one hour. The information from the interview is being used to create a field guide entry with select portions of those interviews being used in a journalistic fashion to create the entry. This is not central to this paper.

The interviews of interest in this paper were conducted by the project's Multi-Campus Coordinators (MCC). The interviewees were, at this stage, educators serving as principal investigators of CPREE work on their campuses. The function of interviewing the campus PIs was to introduce the protocol and practice before PIs would in turn conduct these interviews with colleagues on their campus. Informal comments from the PIs about the value of the experience spurred our deeper investigation into the ways that the PIs had experienced the interview.

The experience of being interviewed

Several weeks after each of the campus PIs participated in, observed, or conducted discussions using the CPREE discussion kit, they were invited to respond to an essay request for this paper. The essay prompt below generated the foundation for this paper. Additionally, if PIs felt it was apparent, they could connect their experience with a larger issue or challenge in engineering education. The exact prompt read as follows:

Prepare a $\sim 500$ word essay centered on your experience of being interviewed by the MCC about a reflection activity. The core of the essay should be about your experience with the interview -- what it was like to be interviewed, what thoughts you had about reflection during the interview and whether it changed your prior perspective, and what's happened since. To the extent possible, also try to connect your essay to one larger issue/challenge in engineering education. Yes, you could address more than one issue, but we anticipate there would be more depth if you chose to focus on one issue.

The essays represent phenomenological accounts [2]. Researchers have used the phenomenological approach to understand experiences of students and educators; the approach is applicable for our work with engineering educators' experiences. For example, the phenomenological approach was used in Martin's 2009 study exploring the experience of firstgeneration college students pursuing engineering [10]. The study included twenty-four first generation college students, and twenty-two continuing generation college students questioned in a semi-structured interview to discuss their influences for choosing to major in engineering, and the experience of coming to their university. Through the theoretical perspective of social capital, several common themes were identified from interview transcripts. Another example is Borgford-Parnell's work investigating how highly effective university faculty conceive teaching 
[11]. This study included eight university faculty and identified the similarities and complexities of their "Teaching Lifeworld."

\section{Whose perspectives?}

The request was offered to all PIs in our consortium; seven of the PIs were able to participate. The participants are the co-authors of this paper, and their essays are reproduced below in the results section. Three of the co-authors/essay writers work at research extensive institutions (i.e., authors Carberry, Yasuhara, and Csavina), two work at teaching-focused (i.e., authors Harding and Cunningham), and two work at associate's degree granting institutions (i.e., authors Faust and Bankhead). This sample reflects the underlying structure of our consortium; twelve partner campuses including four research-extensive, four teaching-focused, and four associate's degree granting institutions. The sample also reflects the types of national institutions involved in engineering education.

\section{Building insights across the perspectives}

In a multiple perspectives methodology, participating group members come together around their shared perspectives in order to gain a deeper understanding of the phenomenon in question. Making sense of the individual experiences was a collaborative endeavor for the team involved in this paper. All authors were invited to look for themes across the essays (stimulated by the email included below) and raise those to the group. An iterative analysis of the shared ideas enabled us to arrive at a description that captures the spirit of the individual experiences and connects the seven essays together.

Hello All -- Thanks to everyone for your patience as we organize a plan for the ASEE paper. After reviewing the reflective essays you wrote, thinking about the time we have available, and realizing how hard it is to schedule a joint meeting, here is what we propose.

Paper: We address two questions in our ASEE paper (1) What types of experiences might be associated with being interviewed about a reflection activity, (2) What larger scale issues surface when reflecting on interviews about reflection activities?

While we've already noticed patterns across your reflective essays for each of these questions (i.e., patterns in your experiences, and patterns in the types of larger scale issues), we would like to get your help in seeing the patterns more clearly.

So, here is our "ask:" By xxx (but this Friday would be great), please: (a) Read your colleagues' submissions on the Google drive, thinking about connections between what you wrote and the other 1-page submissions, (b) Identify two or more ways in which your experience was similar to one or more of your colleagues' experiences, (c) Identify two or more larger reflection related issues that are common between your essay and one or more of your colleagues' essays, and (d) Post your thoughts to the Google Document - Looking for Themes.

Situating the approach

The experiences of the seven CPREE PIs are not presented as indicative of what the experiences will be of other educators. In other words, we do not claim the results as generalizable. Their experiences do provide a basis for imagining what is possible. Given the interpretivist nature of this work, credibility and transferability are appropriate criteria for evaluating the results that follow $[12,13]$. The collaborative nature of this work represents a form of peer scrutiny, something understood as contributing to credibility. Also, the extensive context provided above creates a solid foundation for readers to make judgments of transferability. 


\section{Multiple Perspectives: The Essays}

In this section, we have included the seven essays in their original form. This format is out of respect for the contributions and also to allow the reader to experience these essays in their original coherence. We have grouped the essays to support the flow of this paper and echo aspects of what we have presented thus far. The groupings are titled as follows: (1) challenged to reflect/required reflection, (2) uncomfortable, awkward, nervous, excited, (3) growing appreciation/my perception has expanded, and (4) my journey. We invite the reader to enjoy the essays.

Challenged to reflect.../ ...required reflecting...

In the first two essays below, Trevor Harding and Adam Carberry describe their experiences of being interviewed about activities with which they have much experience. A significant feature of these essays is the explicit calling out of the interview as a reflection opportunity. In the first essay, Trevor likens the experience to "action research wherein the interviewee was challenged to reflect on their own practices, potentially inspiring them to modify these practices." Adam is equally explicit in his essay, when he states, "Being interviewed about my use of a reflective practice required a great deal of reflecting.."

Trevor Hardin, California Polytechnic State University-San Luis Obispo. My interview with the MCC at the University of Washington, was centered on a reflection activity that I use in my Introduction to Materials Engineering course. This course is a required course for most students who enroll in it and typically has 230 students enrolled at one time. I first introduced reflection to this course about 8 years ago on the premise that engineering students rarely have the opportunity to reflect on their lives given the intense nature of the curriculum. To accomplish this I give students the option of responding to reflective prompts at three levels: 1) reflect on your results from a learning styles inventory and what this says about you as a learner past and future, 2) reflect on what it means to be a whole human being and what being whole might make possible, and 3) reflect on any aspect of your life that is personally meaningful to you. This three tiered approach is designed to allow students the freedom to reflect on what intrinsically motivates them, rather than on a forced prompt. You'll also notice that I do not ask students to write specifically on the content or structure of the course. The goal is to get students reflecting, with the hope that by reflecting on what is important to them they will continue to reflect actively beyond the boundaries of this particular course.

I found the interview process with the MCC to be enlightening. What I noticed about the interview is that it was a sort of action research wherein the interviewee was challenged to reflect on their own practices, potentially inspiring them to modify these practices. I found myself most intrigued by two central issues to my own reflection activity: how do I justify to others my allowing students to reflect on anything they wish in an engineering course, and how and why do I grade the students' reflective products. On the first note I have come to realize that I use reflection in my own courses because I have found reflection to be personally meaningful and beneficial, not because I am after some more specific learning objective. Is this sufficient justification to allow students to reflect on non-course specific subjects? I continue to ponder this question, but I realize that often in engineering courses we teach content that faculty members, from their experience, value as "useful" knowledge and we teach in ways that we believe are effective, again based on our experience. If I believe that the practice of reflection is useful in the lives of our students, then do I not have a duty to help them develop this practice? Is this within the purview of an engineering educator? If we are to educate engineering students to better interact with their world in the future, should we not be working with them to develop their reflective capacity? I continue to struggle with these questions, but I am grateful that the interview with the MCC got me thinking about them.

On the second question of grading, I have given less thought. Currently I assign students a B if they simply complete the assignment and then I assign higher grades based on a loose definition in my mind of the "thoughtfulness" of the reflection. Since the interview I have been wondering if this is an 
appropriate metric for grading and whether I should grade the reflections at all. It would be wonderful to remove the extrinsic motivation of grades from the equation and have students reflect simply from the desire to improve themselves as people and as engineers. However, I worry that many students will not put the energy and thought into reflections if there is not a grade attached to it. Perhaps I will have to experiment with this in the future.

Adam Carberry, Arizona State University-Polytechnic Campus. Being interviewed about my use of a reflective practice required a great deal of reflecting on my part prior to and during the interview. Defining reflection for the interview caused me to reconsider why I decided to implement reflection into my courses in the first place. It has caused me to now continually think about my use of reflection in my courses. What am I trying to get out of such activities and how do I decide if something reflective is worthwhile? There are now three things that I immediately reference: 1) my own teaching experiences, 2) my reading of Schön's "The Reflective Practitioner, " and 3) redesign in engineering design. Each of these components ties together a common thread that learning is enhanced when we look back at what we've done and try to make sense of it. This thought point is something that helps me ensure that my courses provide students with an opportunity to envision how the content they are learning is applicable in the real world.

This simple starting question was an essential springboard for the remaining interview questions. The interview was very relaxed likely because of my previous relationship with MCC Brook Sattler, my previous experience interviewing and being interviewed, and my comfort in implementing my reflective practice, muddiest point reflections. This activity is easily framed as an activity that helps students make sense of an experience. This is one larger issue/challenge I believe engineering education faces. Students who choose to enroll in engineering programs often approach their courses to absorb as much information as they can, so they can pass the exams and get an $A$ in the course. The knowledge "learned" often lacks depth, which leads to students having difficulty recalling or adapting what they learned to further challenges. This is why engineering education needs to further adopt active pedagogical approaches framed by real world examples to provide students with memorable experiences.

The interview also helped me further explore the benefit I receive as an instructor from student reflections. Reflection should not just be reconsidering technical content; it is an avenue for an instructor to revisit pedagogy, execution, and scaffolding of content. Another larger issue/challenge in engineering education is when engineering faculty assume that students have learned the content if they have said it in class. This naïve approach to teaching is something that plagues traditional programs that utilize teacher-centered approaches (e.g. lectures). This issue is in part due to the lack of training that faculty receive prior to being expected to teach. The reflective activity I utilize helps me better grasp what students have learned, so that we, as mutual stakeholders in the class, are on the same page about what has been attained.

Since the interview, I have discussed with other colleagues their use of muddiest point reflections. I have found that most are averse to doing anything in their classes that requires more time, but that this approach is simple and low effort. They did not realize how helpful such a simple activity could be in both better understanding their students' learning and their own teaching practices.

Uncomfortable, awkward, nervous, excited...

In the next essays, Doug Faust and Patrick Cunningham describe their experiences of being interviewed. A significant feature of these essays is how the essays include affective aspects of the experience. In the first essay below, Doug refers to the experience as uncomfortable and awkward. In the second essay, Patrick mentions being excited, being nervous and being concerned about the worth of his activity. While reflection does not necessarily entail this type of affective engagement, such engagement can be an important part of a reflection activity.

Doug Faust, Seattle Central College. I found my experience of being interviewed about a particular classroom activity to be very useful and a little bit uncomfortable, honestly. While I always enjoy talking about teaching, I actually did feel somewhat awkward going through the interview process. At 
first, I attributed this to the fact that we (instructors) are typically the people asking questions and that we have complete dominion over both our classrooms and our instructional decisions. Secondly, almost by definition, a the precondition of a reflection activity is poor student performance, so in a sense we're talking about rectifying a failure.

I now feel like there was another reason why I didn't have as glib and straight-forward answers during the interview as I might have expected. Even though I was given the interview prompt before the meeting and had selected a classroom activity which I had administered many times, the dialog and follow-up questions during the interview forced me to consider a series of new issues or reconsider previous assumptions about my activity in rather stark terms. For example, when I describe my activity casually to coworkers, I say that I allow students to rework their exams and do exam reflections "when they perform poorly". During the interview, it became clear that the reflection activity was a little bit more proactive than reactive. That is to say, that I have been making exams with more difficult problems because I know that the reflection-and-correction process has been very beneficial to students. I can use this exam/post-exam model to work my students up to highstakes, high-difficulty problems in preparation for their professional lives. Since then, another instructor has referred to this practice as purposefully trying to get students sick so that they learn how to stay healthy.

Additionally, the interview gave me some insight about why I found the activity of exam corrections and an exam wrapper - though a rather common practice - to be meaningful. The exam corrections fostered a collaborative atmosphere. The ability to work in groups, especially without being prompted, is one of the skills that practicing engineers have identified to us over and over again as being important and under-emphasized in their undergraduate education. In short, the interview helped me crystallize the idea that I have an image of an engineer as a technically-competent individual who can work, both alone and in a group setting, undaunted by difficult problems and setbacks and that this activity had been tweaked and crafted to advance students towards realizing that image.

Since the interview process started, I have reworked some of my teaching activities in this and other classes. Further, our department is holding one of our CPREE meeting/workshops specifically on issues related to group work in our engineering and pre-engineering classrooms. In our first plenary meeting, we spent time talking about what our image of successful students is: what changes we wish to affect in them over the term. All of these were set off by the process of reflecting on reflecting.

I do think this is actually connected to a fundamental issue in education - that the curriculum we generate for students is informed by an image of what sort of people we want to produce at the end of the educational or training process and that for instructors to take the time to reflect on what that image is pays dividends in their curriculum development and overall effectiveness. I know that I personally now feel that I have greater clarity on the student-image I'm trying to create and that it helps me choose and develop appropriate educational materials.

Patrick Cunningham, Rose-Hulman Institute of Technology. Leading up to my interview with our MCC, I wondered if I had done anything worthy of being interviewed about. I have long been interested in helping my students to engage the material in my classes whether they intended to or not, and I have sought ways to do this. Most of the reflection I have had my students doing was informal on in-class activities or discussions. For example, having students explain, dissect, and model lancing devices for diabetic blood testing to introduce a course on analysis and design of engineering systems or asking students to develop reasons for investigating various differential equation models for a given gear train. Why do we need to know the dynamics of the interaction forces between the gear teeth? Why would we need to know the input torque requirements for a prescribed speed change? In the end, I settled on a more recent and more formal reflective activity, a student concept mapping assignment on skills involved in ill-structured problem solving, which was a culminating element of a six-week experience working to solve authentic engineering problems.

I was nervous and excited about the interview. I wondered if this reflective activity was good enough. It was a new activity in a new course, and, though it was grounded in solid theory about how learning works, it has not gone through the refinements of practice. I had worked very had developing the assignment and the activities leading up to it and student work showed notable progress in their conceptions of problem solving. Such things are fun to share.

During the interview I found I needed time to think and ponder the questions, even though I had 
previewed them. Remembering and reflecting takes time and the right environment. Often, as I was answering a later question I would recall a connection or a detail that went with an earlier question. In the back of my mind I asked myself if I was giving my students time to think and ponder in my classes or did I just expect them to ponder on their own, outside of class time?

As we talked about my reflective assignment I also found myself processing it anew and understanding it in new ways. We are reflective professionals who are seeking to develop reflective students so they can become reflective engineers. My most poignant experience of the interview came toward the end when we were working through the questions on translating the reflective activity into the consortium framework. I paused when my MCC asked, "What was done to help the students arrive at a meaning?" I was not sure. At first I was disappointed. I had missed something. Did that make the assignment a failure? Then I was heartened. This is one of the elements that I discussed with colleagues as we processed how the new class went. There was a need to bring closure to the assignment and the six-week module for the students, a chance to process it and make sense of it with them. Subsequent iterations have made time and space for this in the class.

The importance of helping students make meaning of their experiences in engineering classes has stuck with me. It is this sense of meaning and importance that help lessons stick in students' minds and to be available for transfer to new problems. It also helps students to be motivated to persevere through challenges. Traditional engineering education has been so content driven that we have left the development of meaning out of formal instruction. We leave its occurrence up to chance. It was certainly missing from my undergraduate engineering experience-To me, formal instruction on meaning means giving time and assignments [letting the students know it is important and we expect it] focused on aiding students to develop the context for what we are teaching. Why are we asking them to do (insert content here)? Why does it matter to anyone? To them? Why should they care? Students with thoughtful and reasoned answers to these questions will be better poised to dig into the material and access it again on new problems where it may be applicable while sticking it out when their education feels challenging.

Growing appreciation/My perception has expanded...

In the next two essays, Ken Yasuhara and Kristine Csavina describe their experiences. A significant feature of these essays is the explicit naming of their growing understandings of reflection. Their perspectives are complementary. Ken Yasuhara speaks of reflection in terms of the potential to support "integration in time and integration in the person," while Kristine Csavina highlights the potential for reflection activities across the curriculum to serve as a "tool to guide the iterative process of learning." In both cases the essay writers connect their interview experiences to their growing or evolving understanding.

Ken Yasuhara, University of Washington. Integrative learning through reflection. Prior to my discussion with Lauren, I had already spent a considerable amount of time thinking about reflection in engineering education during the proposal process for CPREE funding. Discussing a specific reflection activity [redacted for blind peer review] in the specific context of an online workshop series on engineering education ended up being a helpful reminder of how much care and effort it takes to go from that earlier, largely conceptual thinking to real impact on learning. Perhaps because of my own engineering background and my experience working at the Center for Engineering Learning \& Teaching (CELT), I have long found it useful (not to mention natural) to approach teaching as a design exercise - designing learning experiences to meet specific goals and constraints. As I learn more about reflection with my colleagues at CELT and in CPREE, I have a growing appreciation for the need to design reflection into learning experiences, to the point where I feel that there is tremendous unmet potential for learning in the formal and informal experiences that engineering students have today.

One feature of reflection that has made it such a crucial item in my "learning design toolbox" is its potential to both create and make visible a wide range of connections - what I might call integration in time and integration in the person (phrases I arrived at after talking with Lauren). Regarding the former, I described to Lauren my hope that the reflection activity we discussed helped the learners in 
question-graduate students interested in engineering education-relate their experiences in an online workshop to prior experiences and knowledge about engineering education, as well as to anticipated experiences in their academic careers. Ideally, learners would gain more from the online workshop experiences by understanding them in this larger temporal context.

What I am calling integration in the person is another kind of connection that I discussed with Lauren: the potential to integrate the cognitive, affective, and conative domains. The reflection questions posed to the learners invited them to be aware of not only learning concepts and skills but also affective experiences like surprise and encouragement/discouragement, as well as how all of this related to their goals and how they intended to pursue them. As I told Lauren, I strongly believe in the value of this kind of broadly encompassing reflection, and I hoped that the repeated practice with the reflection activity that we designed into the workshop series might even begin to reinforce a more generally applicable habit.

Talking with Lauren about these integrative qualities of reflection led me to mention another feature of reflection that makes it particularly interesting and appealing to me personally. As education in engineering (but not just) seems to move toward emphasizing a wide range of experiences (e.g., research, internships, service learning, teaming, labs, design...the list goes on), I perceive a risk of forgetting the profound value of simply pausing to consider, "What's going on here?" As a practicing Buddhist, I think I see some parallels between reflection as I have described it above and the awareness practices (meditation being the most prominent) that are so central to Buddhist understandings of psychology, suffering, and much more. I try to keep my eyes open to opportunities for my understandings and practices of reflection and meditation to inform each other. For now, I will offer this: that both seem imbued with quiet humility - that there is more to be learned from an experience than meets the mind's eye-coupled with firm faith in the human capacity to attain that learning.

Kristine Csavina, Arizona State University- Polytechnic Campus. My perspective of the interview process is as an observer-observing the interviewee and the interviewer (over the phone) and learning how to use the discussion kit. The process of documenting the interview seemed overwhelming at first, in the sense of recording the interview at the pace of the discussion and capturing sufficient details, but, in time, this was no longer the perception. The guided questions in the kit keep the interview relaxed and moving forward. Alternatively, the script at the start of each section seems forced and somewhat unnatural, and continues to feel that way as we progress with our interviews. A few bulleted phrases about the next series of questions might be best, though I do not feel pressured to use the script. The one piece of the interview that continues to be difficult to effectively capture during the interview is "Translating the Reflective Activity." While the "experience" and "meaning" are readily articulated, the other three sections (features, lens and action) are reflective activities for the interviewer and take practice to formulate by the end of the interview. I have not mastered this portion of the interview and prefer to take time after the interview to best document this translation piece.

My initial thoughts of reflection activities were that they served (1) as end-of-semester activities completed individually and (2) as a means for me to understand misconceptions or lack of depth of understanding, helping me to improve my next course offering. Since participating in several reflection interviews with my colleagues, my perception of reflection has expanded to understand reflection as a tool to guide the iterative practice of learning. Reflections can be individual assignments or class activities (even conducted in teams) completed at the end of class, at the end of a class activity, at the end of module or end of course. Reflective activities not only gage what students learned measured against the instructor's expectation, but also are likely used more appropriately as a guided exercise. These activities at a minimum serve to help students reflect on what they did not understand but more pointedly as "closing the loop" activities to embed deeper understanding reflecting on initial understanding, the process of gaining the knowledge, the depth of understanding, and how the information might be used again in the future. These activities help students understand that learning is an iterative process and emphasize that how they learn may be as important as what they learn. If students are encouraged to use this practice outside the "class activity" or "course assignment," students may be more empowered to self-direct their learning across courses and beyond, encouraging a practice of life-long learning through reflection. Helping students to self-direct the reflection of their own learning may help with issues of persistence, especially in engineering 
where ideas can be abstract. Guided reflection activities, deliberately placed early in the curriculum with thoughtful feedback from the instructor, may help instill the practice of reflection throughout the student's academic life (and beyond).

\section{My journey...}

The final essay, like the second essay in the previous section, emphasizes the chance to interview other educators/document the reflective practices at one institution. In the essay, Richard Bankhead describes himself as on a journey through literature and theory, and through myriad discussions. What is notable in the essay is the final observation, "if I had been asked to participate in a grant-funded project where I would have been asked to participate in a class or discussion on student motivation and learning theory, I would have most likely declined." The chance to reflect and talk to other colleagues has engendered a chance to review the very same literature and theory.

Richard Bankhead, Highline College. As a participant in the CPREE project centered on capturing reflective practices I have had the opportunity to document the reflective practices that we use in our engineering classes. In those practices we ask students to reflect not only on the content they are learning, but also on the process through which they learn. Driven by the desire to be more effective at helping our diverse population of students reach their educational goals, I have also spent considerable time reflecting on how my students learn and, more importantly, how my teaching practices impact their learning.

I have experienced, reflected, conceptualized and experimented in much the same way Kolb proposed in his cycle of learning. My journey has carried me through a multi-disciplinary literature review of intrinsic motivation, self-determination, adult learning theory, and reflection. It has included numerous discussions with colleagues as well as considerable time engaging with students on the subject. New approaches were synthesized from my new understanding of student learning and my prior personal experience as an educator, professional, and student.

In truth, I have spent considerably more time thinking about (reflecting on) the effectiveness of the reflective practices that we use in our engineering classes than actually documenting the practices. In retrospect, if I had been asked to participate in a grant-funded project where I would have been asked to participate in a class or discussion on student motivation and learning theory, I would have most likely declined. Surprisingly, my participation in the CPREE reflection project has had an incredible impact on how I will approach teaching and learning in the future as a result of my own learning about the importance of reflective practices in education.

\section{Bridging Perspectives: Patterns, Similarities, Commonalities, Larger Issues}

A multiple perspectives methodology allows participating group members to come together around their shared perspectives in order to gain a deeper understanding of the phenomenon in question. The phenomenon for this study was the experience of being interviewed about a reflection activity. The email that anchored our effort used several terms to characterize what we were after: patterns, similarities, commonalities, and larger issues. Here we offer a "map" of the phenomenon (the experience of being interviewed). We focus first on cross-essay observations that speak to the experience of being interviewed as having been an opportunity to reflect. We then turn to three additional observations: reflection on the activities being discussed in the interview, reflection on reflection as a general issue, and the opportunity to bridge to more personal viewpoints and motivations. 
Experienced as reflection

The essays support an argument that the experience of being interviewed was indeed a reflection opportunity. For example, some essays feature explicit statements about the experience being an opportunity to reflect (e.g., "the interviewee was challenged to reflect" from Trevor Harding and "this required a great deal of reflecting" from Adam Carberry). The essays also feature descriptions of the experiences in terms of thinking consistent with reflection as well as affective engagement consistent with reflection. For example, the essays describe the experiences as has having "pushed me to explore," as requiring me "thinking more deeply," and as an opportunity to "explore issues that had not previously been considered." Adam Carberry states "As we talked about my reflective assignment I also found myself processing it anew and understanding it in new ways." Rich Bankhead is also quite explicit: "I have experienced, reflected, conceptualized and experimented in much the same way Kolb proposed in his cycle of learning." Further, the essays contain descriptions of the experience that are consistent with reflection experiences, descriptions of the experience as "awkward," "uncomfortable," "intriguing," "surprising," and "sparking wonderment."

\section{Reflection on the activity}

The essays include references to the educator having come to a refined understanding of his or her activity (reminiscent of Fink et al.'s cycle of professional practice described earlier [3]). For example, Doug Faust speaks of having gained a broader understanding of why and how he had been going about his activity (e.g., "During the interview, it became clear that the reflection activity was a little bit more proactive than reactive."). Patrick Cunningham speaks of having come to a better understanding of a specific aspect of the activity (e.g., "As we talked about my reflective assignment I also found myself processing it anew and understanding it in new ways." and "I paused when my MCC asked, "What was done to help the students arrive at a meaning? I was not sure."). Adam Carberry reports having found himself talking more with other educators as a result of having the chance to explore his own thoughts during the interview (e.g., "Since the interview, I have discussed with other colleagues their use of muddiest point reflections."). Trevor Harding questioned how he justified his activity (e.g., "how do I justify to others my allowing students to reflect on anything they wish in an engineering course") and also how he graded his activity (e.g., "Since the interview I have been wondering if this is an appropriate metric for grading and whether I should grade the reflections at all."). Looking across the essays, it appears that the refreshed and reconsidered view added or enhanced meaning to the activity.

\section{Reflection on reflection}

The essays contain statements about different ways of understanding and appreciating reflection, about new realizations alongside the revisiting of existing ideas, and about the purposes for asking students to reflect. For example, Kristine Csavina described having come to a new understanding of the role of reflection in engineering education (e.g., "my perception of reflection has expanded to understand reflection as a tool to guide the iterative practice of learning.") Ken Yasuhara describes his evolving way of understanding the outcomes of reflection for students, an evolving understanding that he shared during the interview (e.g., "One feature of reflection that has made it such a crucial item in my "learning design toolbox" is its potential to both create and make visible a wide range of connections - what I might call integration in time and integration in the person."). Adam Carberry mentions the core references he draws on when thinking about reflection (e.g., "There are now three things that I immediately 
reference: (1) my own teaching experiences, (2) my reading of Schön's The Reflective Practitioner, and (3) redesign in engineering design.") Of particular note, Patrick Cunningham draws attention to a significant challenge (and perhaps a design opportunity) associated with integrating reflection into engineering education - the idea that we currently leave the general issue up to chance (e.g., "Traditional engineering education has been so content driven that we have left the development of meaning out of formal instruction. We leave its occurrence up to chance. It was certainly missing from my undergraduate engineering experience.")

\section{A chance to bridge}

Multiple essays include content that bridges either the reflection activity or the general issue of helping students reflect with more personal elements including individual beliefs about education, goals for being an educator, and personal stances that make reflection relevant for the educator. Consider the following:

- Patrick Cunningham: "We leave its occurrence up to chance. It was certainly missing from my undergraduate engineering experience."

- Doug Faust: "I do think this is actually connected to a fundamental issue in education that the curriculum we generate for students is informed by an image of what sort of people we want to produce at the end of the educational or training process and that for instructors to take the time to reflect on what that image is pays dividends in their curriculum development and overall effectiveness."

- Trevor Harding: "On the first note, I have come to realize that I use reflection in my own courses because I have found reflection to be personally meaningful and beneficial, not because I am after some more specific learning objective. Is this sufficient justification to allow students to reflect on non-course specific subjects? I continue to ponder this question, but I realize that often in engineering courses we teach content that faculty members, from their experience, value as 'useful' knowledge and we teach in ways that we believe are effective, again based on our experience. If I believe that the practice of reflection is useful in the lives of our students, then do I not have a duty to help them develop this practice? Is this within the purview of an engineering educator? If we are to educate engineering students to better interact with their world in the future, should we not be working with them to develop their reflective capacity?"

- Ken Yasuhara: "As a practicing Buddhist, I think I see some parallels between reflection as I have described it above and the awareness practices (meditation being the most prominent) that are so central to Buddhist understandings of psychology, suffering, and much more. I try to keep my eyes open to opportunities for my understandings and practices of reflection and meditation to inform each other. For now, I will offer this: that both seem imbued with quiet humility - that there is more to be learned from an experience than meets the mind's eye - coupled with firm faith in the human capacity to attain that learning."

- Rich Bankhead: "In retrospect, if I had been asked to participate in a grant-funded project where I would have been asked to participate in a class or discussion on student motivation and learning theory, I would have most likely declined. Surprisingly, my participation in the CPREE reflection project has had an incredible impact on how I will approach teaching and learning in the future as a result of my own learning about the importance of reflective practices in education." 


\section{Discussion}

To explore the general question of ways to help educators become more reflective, this paper has focused on the proposition that one way to help educators be more reflective is to give them an opportunity to discuss (or be interviewed about) an activity they do with students. In the previous section, we identified the following themes across essays written by educators in which documented their experiences of being interviewed. Their essays suggest that the educators experienced the interview as (1) a reflection opportunity, (2) a chance to reflect on the activity that was the focus of the interview, (3) a chance to reflect on reflection as an educational activity, and (4) a chance to bridge reflection and other points of personal interest.

These themes connect back to the conceptual frameworks introduced earlier. For example, the idea that the educators experienced the interview as a reflection opportunity is significant for connecting back to Fink et al.'s cycle of professional practice [3] and Brookfield's critical reflection [4]. The observation that the educators experienced the interview as a chance to reflect on the activity connects solidly to the cycle of professional practice ideal, in that the educators were having a chance to revisit the activity, identify problems, explore the problems, resolve the problems, etc. Finally, the observations that the educators experienced the interview as a chance to reflect on reflection and to connect to other points of personal interest connect to Brookfield's concept of critical reflection. This is particularly evident in the specific issues that were raised in relation to these themes, such as questions about why an educator would require reflection and how reflection is associated with ideals humility and ideas about what type of students we want to graduate. In the remainder of the discussion, we made additional observations about the four themes identified in the previous section. First we made several comments connected to the first theme.

As we have noted, the essays support an argument that the experience of being interviewed was a reflection opportunity. Not only do the essays feature explicit statements about the experience being an opportunity to reflect, the essays also feature descriptions of the experiences in terms of thinking consistent with reflection as well as affective engagement consistent with reflection. Several essays describe actions resulting from the interview experiences - actions suggestive of the experience having been a reflective one.

The significance of the experience being described as reflection lies in the observation that it could have been otherwise. The goal of the interviews was to document reflective practices, so that they could be shared with other educators. That the interviews were experienced as reflection opportunities, rather than simply opportunities to share a reflective practice, may seem obvious in retrospect but this was not an initial intention.

What can we say about why the activity of being interviewed ended up being experienced as a reflection opportunity? Alternately, what do we think about the transferability of these findings beyond the specific interview and the specific educators that have so far been the focus of this paper? We can venture some observations to these questions, but recognize that additional research would be necessary to have definitive answers. In order to think beyond the educators in this paper, it is valuable to think about who they represent - educators interested in reflection specifically and education more broadly, and educators who have an activity to share with others. Such a characterization helps broaden the focus. We are unsure of the number of engineering 
educators who fit this profile, yet it does appear to us that this number is greater than we might have initially thought.

It is also valuable to wonder whether the specific experiences are necessarily tied to the interview having been about a reflection activity (noting that our paper would certainly be easier to articulate if the student activity was about something other than reflection). Would educators interviewed about any educational activity that they have used with students also describe the experience of being interviewed as a reflection opportunity? We believe there is reason to be optimistic that this might be the case. Our interview protocol, which was designed to collect comprehensive information about the reflection activity, also can be seen as quite aspirational in the sense that it has questions for which educators are unlikely to deeply know the answer. By asking respectful and yet probing questions, it seems likely that we set up a promising avenue for inducing reflection. This is particularly intriguing as a mechanism for professional development and/or another means by which educators can support each other. The idea that asking educators about the activities they use via a formal structured protocol can create opportunities for reflection means that we could have a lot more opportunities to help each other than perhaps we had imagined. Having a chance to describe a practice with pride creates a "cover story" that may permit reflection to happen without it being demanded. We might call this planned-incidental reflection.

At the same time, we are struck by the possibility that being interviewed about a student-oriented reflection activity may be particularly suited to engendering educator reflection, or at least have specific properties in terms of creating opportunities for educator reflection. In making this observation, we note that reflection is an ill-defined subject, not currently part of the formal curriculum, can be challenging to support, and has a personal element. The openness and complicatedness of reflection as a subject in engineering education may mean that sharing a reflection activity, relative to sharing other activities, may lead to more or at least distinctive "reflection opportunities."

Connecting to the second, third, and four themes, we note that the content of the essays provides a window into potential educator reflection opportunities associated with being asked to describe a student-oriented reflection activity. Our analysis notes that the content of the essays covered the four topics - the reflection activity, reflection generally, and reflection personally. The breadth of this list is interesting because it could have been otherwise. Since the interview protocol focused on capturing information about the reflection activity narrowly, it was not expected that the interview itself would lead to reflection on broader issues.

It is certainly possible that the breadth of content issues across the essays is somehow specific to the authors of those essays. Those of us involved in CPREE have come together around the issue of supporting student reflection in engineering education. It is interesting to point out that many educators have expressed interest in the role of student reflection in engineering education, and we could expect, at minimum, such educators to cover a similar broad range of topics if they had a similar chance to be interviewed. What may be more important, though, is the chance to realize what the engineering education community can gain from the ideas across the essays. Such issues include: how to grade reflection activities, whether reflection necessarily involves a poor performance, how does reflection fits in with larger education systems defined by technical knowledge and learning objectives, and the role of our own personal stories and personal 
commitments in the larger context of engineering education. There is a chance for the larger engineering education community to think about these and other issues, and, because these ideas come from educators already thinking deeply about reflection in engineering education, these ideas deserve serious consideration.

\section{Conclusion}

In this paper, we describe how an opportunity to be interviewed about an educational activity (specifically an activity to support student reflection) functioned as an opportunity for educators to reflect. The results presented in this paper provide a basis for suggesting that this activity is promising; and we encourage those interested in supporting or promoting reflective educational practice to explore the use of interviews as described in this study. Future research could explore the possibility that the opportunity to be interviewed about anything of personal relevance in teaching might function in a similar way to provoke reflection. The results presented in this paper can also be read as raising important issues associated with supporting student reflection-issues that can be used in the design and refinement of other approaches to supporting student reflection.

\section{Acknowledgment}

This material is based on work supported by The Leona M. and Harry B. Helmsley Charitable Trust through funding of the Consortium to Promote Reflection in Engineering Education (CPREE), a collaboration of twelve educational institutions. We also acknowledge and thank the other members of our team who were interviewed.

\section{Bibliography}

[1] Henderson, C., Beach, A., \& Finkelstein, N. (2011). Facilitating change in undergraduate STEM instructional practices: An analytic review of the literature. Journal of Research in Science Teaching, 48(8), 952-984.

[2] Adams, R., Evangelou, D., English, L, Dias De Figueiredo, A., Mousoulides, N, Pawley, A., Schiefellite, C., Stevens, R., Svinicki, M., Trenor, J.M., Wilson, D.M. (2011). Multiple Perspectives on Engaging Future Engineers, Journal of Engineering Education, 100(1), 48-88.

[3] Fink, L. D., Ambrose, S., \& Wheeler, D. (2005). Becoming a professional engineering educator: A new role for a new era. Journal of Engineering Education, 94(1), 185-194.

[4] Brookfield, S. (1995). Becoming a critically reflective teacher. San Francisco: Jossey-Bass.

[5] Schön, D. A. (1983). The reflective practitioner: How professionals think in action. New York: Basic books

[6] Finelli, C. J., Ott, M., Gottfried, A. C., Hershock, C., O'Neal, C., \& Kaplan, M. (2008). Utilizing instructional consultations to enhance the teaching performance of engineering faculty. Journal of Engineering Education, 97(4), 397-411.

[7] Tenenberg, J., \& Wang, Q. (2005). Using course portfolios to create a disciplinary commons across institutions. Journal of Computing Sciences in Colleges, 21(1), 142-149. 
[8] Tenenberg, J., \& Fincher, S. (2007, March). Opening the door of the computer science classroom: the disciplinary commons. ACM SIGCSE Bulletin, 39(1), 514-518.

[9] Turns, J. A., Sattler, B., Yasuhara, K., Borgford-Parnell, J. L., \& Atman, C. J. (2014). Integrating Reflection into Engineering Education. In Proceedings of the 2014 ASEE Annual Conference \& Exposition. Indianapolis.

[10] Trenor, J. M. (2009). A phenomenological inquiry of the major choice processes of an overlooked demographic: First generation college students in engineering. In Proceedings of the 2009 Research in Engineering Education Symposium. Australia.

[11] Borgford-Parnell, J. L. (2006). Conceptions of teaching in a research-intensive university: what effective teachers think (Doctoral dissertation). University of Washington, Seattle, WA.

[12] Shenton, A. K. (2004). Strategies for ensuring trustworthiness in qualitative research projects. Education for information, 22(2), 63-75.

[13] Devers, K. J. (1999). How will we know "good" qualitative research when we see it? Beginning the dialogue in health services research. Health services research, 34(5 Pt 2), 1153. 


\section{Appendix 1. CPREE Interview Protocol}

Note: This protocol is intended for use in interviewing engineering educators about activities they use to support student reflection. The protocol is reproduced verbatim.

Thank you again for participating in the Consortium to Promote Reflection in Engineering Education (CPREE) reflection activity discussion. Working with the CPREE staff, we will use this conversation to create a field guide entry for your reflection activity. There are two field guides: one for our campus and national field guide, which will contain entries from CPREE partner campuses. Once we have completed the entry, I will send it back to you for review.

[At this point, use the consent process that has been determined as appropriate for your campus.]

In this discussion, I will first ask you about your professional background. Then I would like to hear about your view of reflection in education. Next, I want you to think about a reflection activity and one time that you did it. I will ask you to describe this reflection activity, the rationale for using it, the students' reaction to it, and the outcomes. Do you have any questions before we begin?

\begin{tabular}{|c|c|c|}
\hline $\begin{array}{l}\text { First, tell me about your role here } \\
\text { and how you came to the campus? }\end{array}$ & Notes & Time \\
\hline $\begin{array}{l}\text { Possible follow-up questions: } \\
\text { What department are you in? } \\
\text { teaching or working with students? } \\
\text { What is something [distinct, } \\
\text { unique, important] that you bring to } \\
\text { the classroom? }\end{array}$ & & \\
\hline $\begin{array}{l}\text { Reflection is often a topic for which } \\
\text { educators have varying definitions. } \\
\text { How do you define reflection? }\end{array}$ & Notes & Time \\
\hline $\begin{array}{l}\text { Possible follow-up questions: } \\
\text { What comes to mind when you } \\
\text { think about reflection? } \\
\text { What kinds of reflection activities } \\
\text { have you done with your students? } \\
\text { How do you choose? }\end{array}$ & & \\
\hline
\end{tabular}


- What do hope or expect will happen as a result of these activities?

\section{Discussing One instance of A reflection activity}

\begin{tabular}{|c|c|c|}
\hline $\begin{array}{l}\text { Thank you for helping me } \\
\text { understand your perspective on } \\
\text { reflection. } \\
\text { Now I would like you to walk me } \\
\text { through one instance of a reflection } \\
\text { activity you have used with } \\
\text { students. }\end{array}$ & Notes & Time \\
\hline $\begin{array}{l}\text { Possible follow-up questions: } \\
\text { Context } \\
\text { in? What class does this take place } \\
\text { individual or group activity? } \\
\quad \text { Was it graded? } \\
\text { Additional Details } \\
\quad \text { What did you call the activity? } \\
\text { Did you provide written } \\
\text { instructions in advance? } \\
\text { technology did you use? } \\
\text { Reactions or Responses } \\
\text { Did the reflection activity change } \\
\text { what you did in the class? If yes, how } \\
\text { so? } \\
\text { Did anything surprise you? } \\
\text { What are you most proud of? }\end{array}$ & & \\
\hline
\end{tabular}




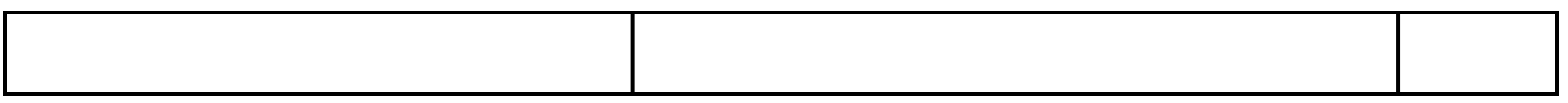

\begin{tabular}{|l|l|l|}
\hline Why did you implement it? & Notes & Time \\
\hline $\begin{array}{l}\text { Possible follow-up questions: } \\
\text { Where did you get this reflection } \\
\text { activity? }\end{array}$ & & \\
$\begin{array}{l}\text { What inspired this reflection } \\
\text { activity? }\end{array}$ & \\
$\begin{array}{l}\text { How has this reflection activity } \\
\text { changed over time? }\end{array}$ & & \\
\hline
\end{tabular}

[Summarize what was discussed in a few steps with the educator for confirmation.]

Try to summarize what was discussed in a few steps with the interviewee for confirmation.

\begin{tabular}{|l|l|l|}
\hline $\begin{array}{l}\text { What are some tips or tricks that } \\
\text { you would share with another } \\
\text { educator? }\end{array}$ & Notes & Time \\
\hline $\begin{array}{l}\text { Possible follow-up questions: } \\
\quad \text { What is important about this } \\
\text { reflection activity to maintain its } \\
\text { structure? }\end{array}$ & & \\
$\begin{array}{l}\text { Do you have any suggestions for } \\
\text { improvement? }\end{array}$ & \\
$\begin{array}{l}\text { What are the challenges or } \\
\text { difficulties associated with this } \\
\text { reflection activity? }\end{array}$ & \\
$\begin{array}{l}\text { Have you talked about this } \\
\text { reflection activity with your peer } \\
\text { educators? }\end{array}$ & & \\
\end{tabular}




\section{Collecting Digital Library Content}

[Gather artifacts the educator uses to support this reflection activity (e.g., templates, hand-outs, presentations, examples to be shared for the activity, etc.).]

\begin{tabular}{|l|l|}
\hline Item Name & Description \\
\hline & \\
\hline & \\
\hline & \\
\hline & \\
\hline & \\
\hline & \\
\hline
\end{tabular}

\section{Translating the Reflection Activity}

[Translate the activity into the reflection framework as a way to recap the discussion. If needed, use the definitions in the box below from the ASEE paper "Integrating Reflection into Engineering Education." The question prompts in the subsequent box will help you and your colleague frame the activity.]

Experience: An experience can be understood as engagement with the world, roughly circumscribed by time. For example, we can think about the experience of getting good news, the experience of doing homework, the experience of traveling abroad, and the experience of being a teenager.

Features: Features of an experience are those aspects of an experience with which an individual is aware. Put another way, the features of the experience are those that can be described by an individual. For a given experience for example, we might be aware of the time involved, what surprises us, our physiological response, etc.

Lens: We use lens to refer to the knowledge that is being used to interpret or make meaning of specific features of an experience. For example, we can interpret features of an experience using understanding of a particular subject matter (accountable disciplinary knowledge), understanding of self (identity), or determining goals (planning future learning).

Meaning: Meaning refers to the specific understanding of the experience that results from using the lens to interpret the features. For example, a student, reflection on an activity's difficulty (e.g. the feature) using some type of productivity lens, might come to an understanding of ways in which the activity could be done more effectively.

Action: Action refers to steps taken as a result of the meaning that has been ascribed to the experience. In educational contexts, actions might include studying in a different, way, seeking out a professor in office hours, and choosing specific classes to take. 


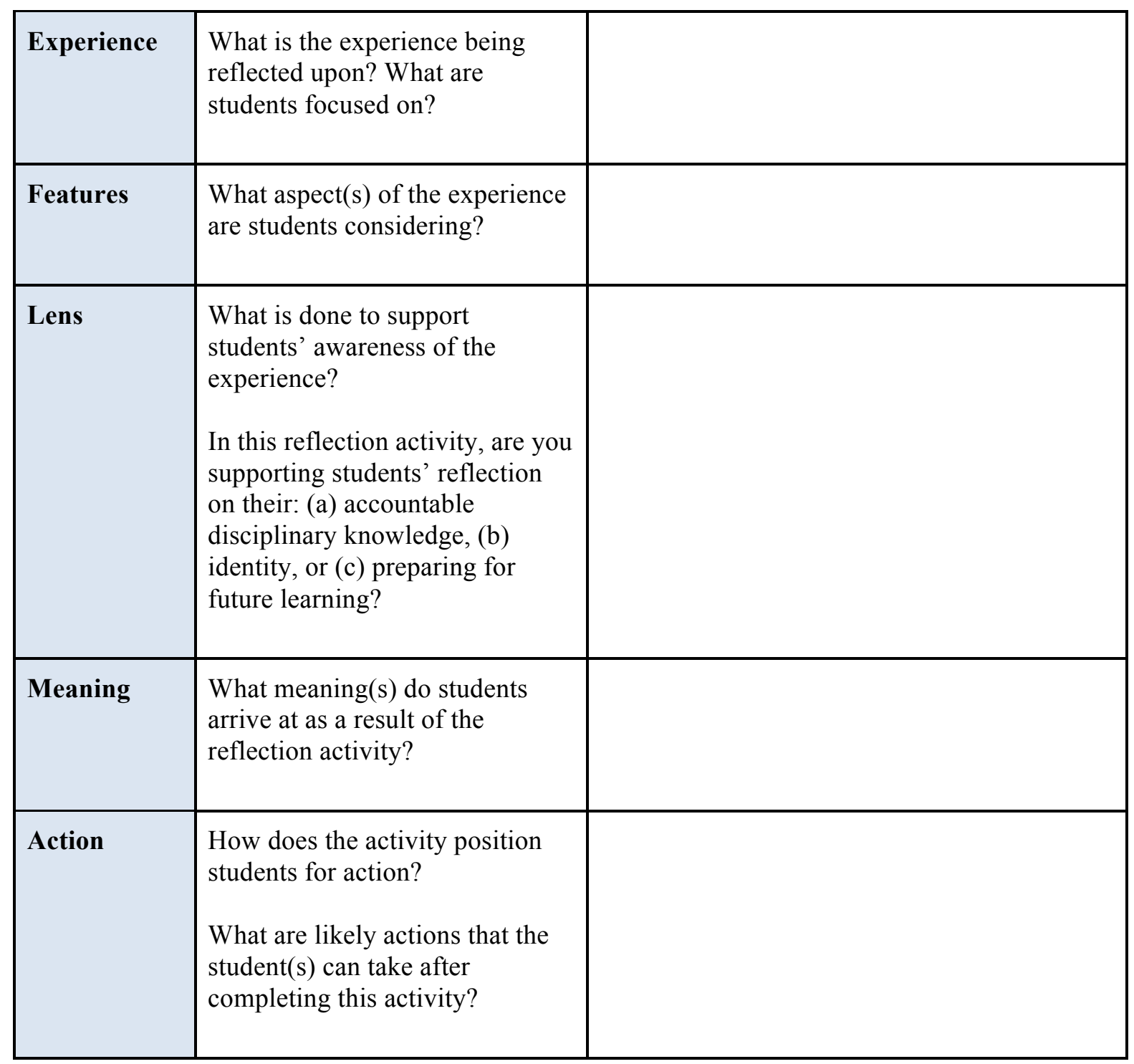

\section{Wrap-Up}

Thank you again for participating in the Consortium to Promote Reflection in Engineering Education (CPREE) reflection activity discussion. Our next step is to draft a field guide entry based on the reflection activity we discussed today. Once a draft is ready, I will send that back to you for approval. 